\title{
Nanoporous polymer liquid core waveguides
}

Gopalakrishnan, Nimi; Christiansen, Mads Brøkner; Ndoni, Sokol; Kristensen, Anders; Sagar, Kaushal Shashikant; Vigild, Martin Etchells

Published in:

2010 Conference on Lasers and Electro-Optics (CLEO) and Quantum Electronics and Laser Science

Conference (QELS)

Publication date:

2010

Document Version

Publisher's PDF, also known as Version of record

Link back to DTU Orbit

Citation (APA):

Gopalakrishnan, N., Christiansen, M. B., Ndoni, S., Kristensen, A., Sagar, K. S., \& Vigild, M. E. (2010).

Nanoporous polymer liquid core waveguides. In 2010 Conference on Lasers and Electro-Optics (CLEO) and Quantum Electronics and Laser Science Conference (QELS) (pp. 1-2). IEEE.

\section{General rights}

Copyright and moral rights for the publications made accessible in the public portal are retained by the authors and/or other copyright owners and it is a condition of accessing publications that users recognise and abide by the legal requirements associated with these rights.

- Users may download and print one copy of any publication from the public portal for the purpose of private study or research.

- You may not further distribute the material or use it for any profit-making activity or commercial gain

- You may freely distribute the URL identifying the publication in the public portal 


\title{
Nanoporous Polymer Liquid Core Waveguides
}

\author{
Nimi Gopalakrishnan, Mads B. Christiansen, Sokol Ndoni, Anders Kristensen \\ DTU Nanotech, Technical University of Denmark, DK-2800 Kongens Lyngby, Denmark \\ Corresponding author: anders.kristensen@nanotech.dtu.dk; Phone: +45-4525 6331, Fax: +45- 45887762 \\ Kaushal.S.Sagar, Martin. E. Vigild \\ Danish Polymer Center, Department of Chemical and Biochemical Engineering, Technical University of Denmark, DK-2800 Kongens Lyngby, \\ Denmark
}

\begin{abstract}
We demonstrate liquid core waveguides defined by UV to enable selective water infiltration in nanoporous polymers, creating an effective refractive index shift $\Delta n=0.13$. The mode confinement and propagation loss in these waveguides are presented.

(C) 2010 Optical Society of America

OCIS codes: (160.5470) Polymer; (230.7370) Waveguides
\end{abstract}

\section{Introduction}

The major highlights in new fields like Optofluidics are the ability to combine optics and fluidics in same platform, opening new frontiers in detection of biological molecules in aqueous solutions. For a more compact and robust optofluidic lab on a chip, integration of liquid and optical elements in the same system is needed. Liquid Core waveguides (LCW) in optofluidics offer fully planar optofluidic lab on a chip devices. The major challenge in using LCW is to use a solid cladding material with refractive index below 1.33. Most extended technologies in this field are Teflon AF cladded LCWs, ARROW waveguides etc $[1,2]$. In this work we present UV defined selective water infiltration in nanoporous (NP) polymers, resulting in liquid core waveguides. In addition to an all NP polymer LCW platform, this method provides freedom in selecting clad material since the core index is higher than index of water (1.33).

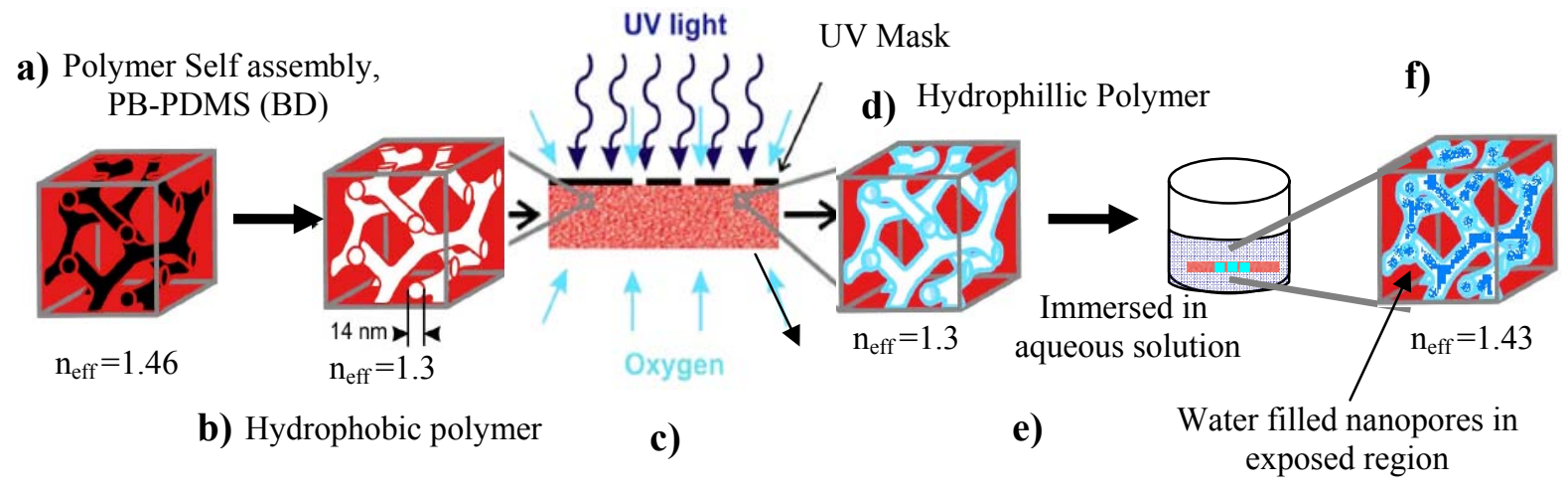

Figure 1.Schematic illustration of working principle of Liquid Core Waveguiding in 1,2-PB nanoporous polymers (a) polymer self assembly of PB-PDMS, (b) minority block etched hydrophobic NP polymer. (c) Selective UV exposure using a UV mask in presence of oxygen (d) hydrophilic polymer in the region of exposure (e) device Immersed in water (f) Exposed region is infiltrated with water changing effective refractive index

\section{Concept:}

The conceptual scheme of nanoporous (NP) LCW is illustrated in Figure 1.The starting material is a self assembling diblock copolymer of polybutadiene (PB) and polydimethylsiloxane (PDMS) (figure 1a). After selectively etching the PDMS minority block, the 1, 2 polybutadiene $(1,2-\mathrm{PB})$ nanoporous polymer with $40 \%$ porosity is obtained (figure 1b). Photo oxidation in the presence of UV light (300-350nm) changes the surface wetting property of the naturally hydrophobic NP polymer. Photo-oxidation in the polymer results in hydroxyl and carboxyl groups at the surface of the pores, making it hydrophilic (figure 1c, d). Increase in effective refractive index $(\Delta \mathrm{n}=0.13)$ due to uptake of liquid at exposed regions is exploited to confine light within the liquid core (figure 1e, f) [3-5]. 


\section{CThW6.pdf}

\section{Results:}

A nanoporous multimode bend rectangular waveguide is defined with $\mathrm{UV}$, to demonstrate the concept of LCW in 1 , 2-PB NP polymer. When immersed in DI water for 30min, the pores in the exposed regions of NP polymer is filled with water, changing the effective refractive index from 1.3 to 1.43 . Figure $2 \mathrm{~b}$ demonstrates guiding of light within the liquid core in wet /water immersed 1, 2-PB NP polymers.

Mode Confinement in NP LCW is obtained by analyzing the intensity variation at the output of the waveguide. A UV mask as shown in figure $2 \mathrm{c}$ is used to define a waveguide with $100 \mu \mathrm{m} \mathrm{X} 100 \mu \mathrm{m}$ cross section. A source of $632.8 \mathrm{~nm}$ is coupled into and out of the LCW using multimode fibers. The detector placed on an XYZ micro translation stage is translated in $\mathrm{X}$ and $\mathrm{Y}$ axis, to observe the intensity variation (figure $2 \mathrm{~d}$ ). Figure 2e clearly pictures the confinement of light in LCW.
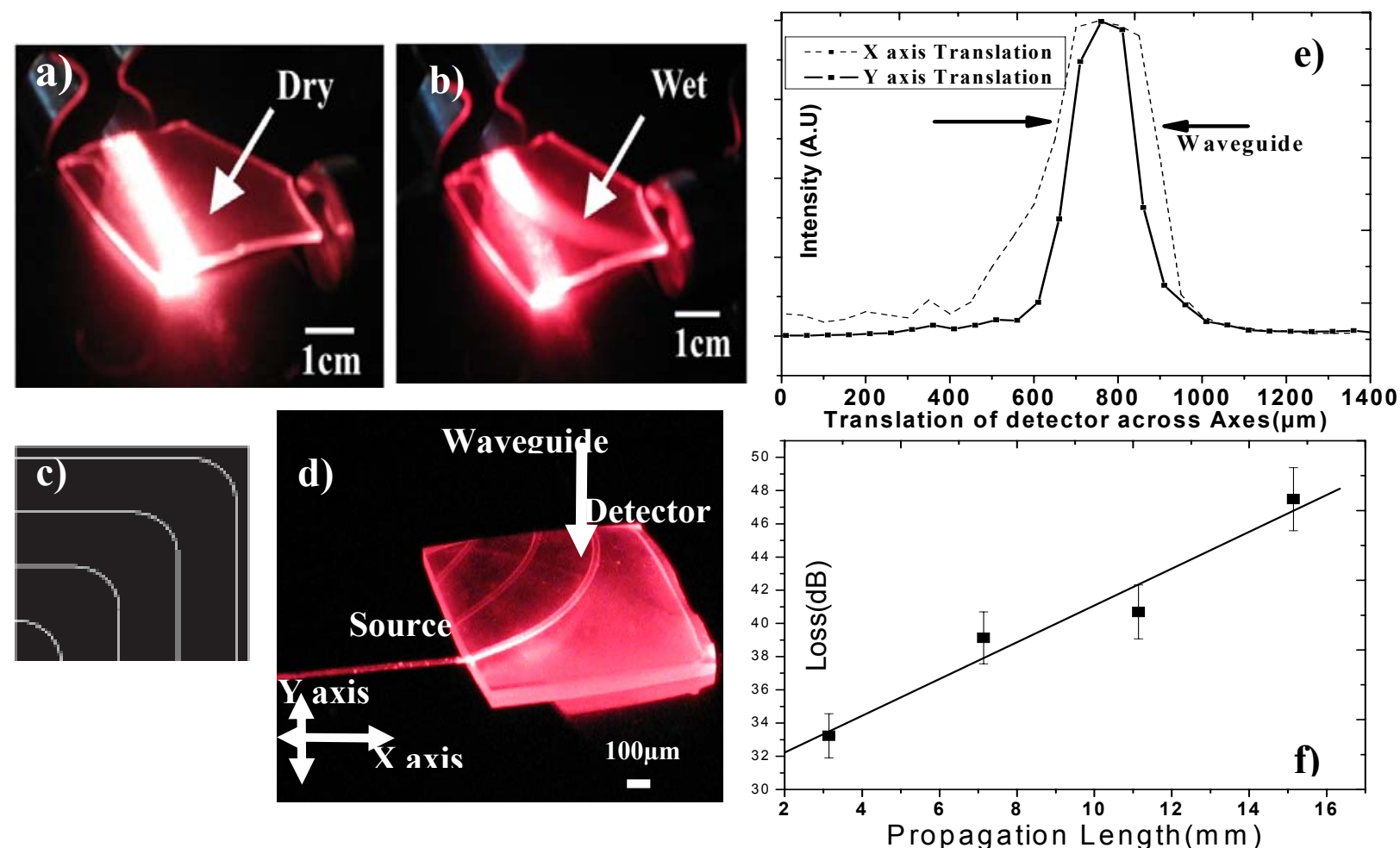

Figure 2. (a-b) Light bends and gets guided in a wet device, while there is no guiding in dry device (d) Experimental setup for measuring waveguide light confinement and propagation loss (e) $\mathrm{X}$ and $\mathrm{Y}$ axis confinement of light (f)Loss in dB in each waveguide vs propagation length, a straight line fit to the data is shown.

Four types of losses occur in bend rectangular waveguides: input and output coupling, transition, radiation and propagation loss. In our work, propagation loss in 1, 2-PB multimode LCW is studied using an inbuilt cutback scheme. The NP polymer is UV exposed using standard UV masks (see figure 2c). Loss in each waveguide is plotted against propagation length (figure 2d). Normalized propagation loss is obtained by subtracting the loss of similarly bend waveguides by removing coupling and bend losses. The propagation loss for straight waveguides in our device is $1,12 \pm 0,42 \mathrm{~dB} / \mathrm{mm}$.

In conclusion, we present the concept for making fully nanoporous LCWs using simple techniques like UV exposure. Infiltration defined index difference in these NP LCW polymers, provide freedom of clad materials. We have also demonstrated confinement of light in these LCWs and have analysed propagation loss.

[1]M..P Duggan, T. McCreedy, J.W.Aylott," A non-invasive analysis method for on-chip spectrophotometric detection using liquid-core waveguiding within a 3D architecture" Analyst.128.11(2003)

[2]M.Holtz, P.K.Dasgupta, G.Zhang."Small-volume Raman spectroscopy with a liquid core waveguide".Anal.Chem.71.14(1999)

[3]S.Ndoni, M. E. Vigild, R. H. Berg"Nanoporous materials with spherical and gyroid cavities created by quantitative etching of polydimethylsiloxane in polystyrene-polydimethylsiloxane block copolymers", J. Am. Chem. Soc. 125.(2003).

[4]M. S. Hansen, M. E. Vigild, R. H. Berg, S. Ndoni, "Nanoporous crosslinked polyisoprene from polyisoprene-polydimethylsiloxane block copolymer", Polym. Bull. 51, 403 (2004)

[5]S.Ndoni, Li Li,, L. Schulte, P. P. Szewczykowskii, T.W.Hansen, F.Guo, R.H.Berg, M.E.Vigild,"Controlled photo-oxidation of nanoporous polymers",Macromolecules,42(2009) 